\title{
Wood smoke exposure and risk of chronic obstructive pulmonary disease
}

\author{
M. Orozco-Levi*, J. Garcia-Aymerich\#, J. Villar", A. Ramírez-Sarmiento*, \\ J.M. Antó ${ }^{\#}$ and J. Gea*
}

ABSTRACT: It was hypothesised that wood smoke exposure could be a risk factor for chronic obstructive pulmonary disease (COPD) in Spain. The present study was designed as a casecontrol study of 120 females requiring hospitalisation during 2001-2003 at Hospital del Mar (Barcelona, Spain).

Cases were recruited from hospital records as females who had been admitted for an exacerbation of COPD. Controls were obtained from pulmonary function test laboratory consultations prior to a surgical intervention. All patients answered a standardised questionnaire.

Exposure to wood or charcoal smoke was strongly associated with COPD after adjusting for age and smoking. The association between length of exposure and COPD suggested a doseresponse pattern. Intensity of exposure in both summer and winter was also related to COPD. Wood or charcoal alone independently increased risk of COPD (odds ratio (OR) 1.8 and 1.5, respectively), but only the combination of both was statistically significant (OR 4.5).

In conclusion, the present study shows a strong association between wood or charcoal smoke exposure and chronic obstructive pulmonary disease, supporting its existence not only in developing countries, but also in European countries, such as Spain. Further studies assessing whether this association also exists in other European societies are warranted.

KEYWORDS: Biomass, charcoal, chronic obstructive pulmonary disease, risk, smoke, wood

$\mathbf{T}$ he household wood-based oven has been extensively used for decades in Spain for both cooking and heating, predominantly in rural areas. During periods of economic crisis, such as in post-civil war times, difficulties in acquiring fuel derivatives increased the use of renewable sources of energy, such as wood and other biomass products. Despite the continuous decrease of the countryside population, $>8$ million people still live in rural areas in Spain. In addition, in recent years, it has become popular to build traditional wood-based ovens in newly constructed homes in suburban areas.

A review of the adverse health effects of ambient air pollution in relation to residential wood combustion in modern societies has recently been published [1]. In this review, BOMAN et al. [1] analysed nine relevant studies, identified from a literature search of PubMed. All these studies focused on the effects of short-term exposure to wood smoke on respiratory symptoms, lung function, asthma and daily mortality [1]. Interestingly, in comparison with the present general estimations for ambient particulate matter and adverse health effects, the relative risks

For editorial comments see page 446 . were even stronger in the studies in which residential wood combustion was considered a major source of particulate matter. Thus, the authors proposed that there seems to be no reason to assume that the effects of particulate matter in areas polluted by wood smoke are weaker than elsewhere [1].

In Spain, chronic obstructive pulmonary disease (COPD) is still more frequent in males than in females [2]. Therefore, it is not surprising that, in patients hospitalised for an exacerbation of COPD, the female: male ratio is still very low $(\sim 1: 9)$. However, a significant proportion of these females $(54 \%)$ were nonsmokers [2]. Based on clinical perceptions and reports of adult patients, the present authors hypothesised that other factors, such as wood smoke exposure, could also participate as a risk factor for COPD in a Spanish population. Therefore, a case-control study of risk factors for the development of COPD in females requiring hospitalisation during 2000-2003 in the Hospital del Mar (Barcelona, Spain) was carried out.

\section{METHODS}

Design

A case-control design was used for the study.
AFFILIATIONS

*Muscle and Respiratory Research Unit (URMAR), Municipal Institute of Medical Research (IMIM), Servei de Pneumologia, Hospital del Mar, CEXS-Universitat Pompeu Fabra \#Respiratory and Environmental Health Research Unit, Institut Municipal d'Investigació Mèdica (IMIM), and

"Servei de Medicina Interna, Hospital del Mar, Barcelona, Spain.

CORRESPONDENCE

M. Orozco-Levi

Servei de Pneumologia

Hospital del Mar

Passeig Maritim 25

Barcelona

E-08003

Spain

Fax: 34932213237

E-mail: morozco@imim.es

Received:

May 032005

Accepted after revision:

November 222005

SUPPORT STATEMENT

This study was supported by a grant from Red RESPIRA (RTIC C03/11,

Fondo de Investigación Sanitaria, Instituto de Salud Carlos III, Madrid, Spain), SEPAR, "Ministerio de

Educación, Cultura y Deporte de España" (Madrid, Spain; grant code 72.129.052). J. Garcia-Aymerich was funded by Red RESPIRA (RTIC C03/11). 


\section{Identification of cases}

Eligible cases were identified from records of the pulmonary outpatient clinic and pulmonary function test laboratory of the Hospital del Mar. For a patient to be enrolled as a case, a diagnosis of COPD was required. The population of cases consisted of females aged $>50$ yrs, born and living in Spain, who required hospitalisation in the Dept of Respiratory Medicine of the Hospital del Mar due to acute exacerbation of COPD during the period 2001-2003. Both active and passive smokers were included. Diagnosis of COPD was performed by assessment of both the signs and symptoms of chronic bronchitis and/or pulmonary emphysema, and functional criteria of chronic and irreversible airflow obstruction (forced expiratory volume in one second (FEV1)/forced vital capacity) $<70 \%, \mathrm{FEV} 1<80 \%$ predicted) and without asthma as assessed by clinical history and response to bronchodilators (change $<12 \%$ in FEV1 following $400 \mu \mathrm{g}$ of inhaled salbutamol) [3-6]. Chronic bronchitis was defined as a cough that was present on most days for a minimum of 3 months $\cdot \mathrm{yr}^{-1}$ and for not less than 2 successive yrs, and when other causes for chronic expectoration had been excluded as the sole cause for the symptoms [7, 8]. The nature and the general purpose of the study were explained to the patient (without revealing any a priori hypothesis) and the questionnaire was administered.

\section{Identification of controls}

For a subject to be enrolled as a control, a diagnosis of COPD had to be absent. The population of controls consisted of females $>50$ yrs of age showing normal pulmonary function tests, who were submitted to the present authors' laboratory during the same study period as a part of pre-surgical evaluations. A frequency matching on age was performed, since age is a known risk factor for COPD. Control subjects who were as close as possible within each age interval to the cases were sought $(50-60,60-70,70-80,>80$ yrs). The patient was contacted and asked for permission to be interviewed and enrolled in the study.

\section{Sample size}

Sample size estimations suggested that 60 cases and 60 controls would allow odds ratio (OR) estimators higher than 3.5 (similar to what had been previously reported) [9] to be obtained for any prevalence of exposure in the control group, considering an alpha risk of 0.05 and beta risk of $<0.20$, in bilateral contrast, and estimating a nonresponse rate of $15 \%$. Bearing in mind the annual number of females with diagnosis of COPD admitted to the present authors' centre, a total of 60 COPD females could be recruited in 3 yrs.

\section{Data collection}

The American Thoracic Society questionnaire was used for the epidemiological studies [10]. It includes the following: demographic information, education, occupational history, and active and passive tobacco exposure. An additional set of questions, previously used in a Spanish population [9], regarding wood and charcoal smoke exposure (length, intensity, summer/winter differences, cooking and type of biomass fuel) was used. Regarding quality of data, cases and controls were interviewed by trained clinicians who were not aware of the hypothesis under study. The present authors ensured that the study population was unaware of the hypothesis of the study and that the structured questionnaire (based on a questionnaire that has been extensively field validated in other settings) made selective recall unlikely. By selecting control subjects from a hospital population, diseased patients were being selected, some of whom may have had diseases associated with the study exposures (e.g. smoking). The present authors tried to minimise this possibility by not selecting controls from the internal medicine wards, but rather from a heterogeneous group of the surgical specialities. All participants gave informed consent.

\section{Statistical analysis}

A comparison of case and control characteristics was conducted using the unpaired t-test (for quantitative variables of normal distribution), the Kruskal-Wallis test (for quantitative variables of non-normal distribution) or Chi-squared test (for qualitative variables). An unconditioned multivariate logistic regression model was used to obtain the association between exposures and COPD, after adjusting for potential confounders $[11,12]$. Interactions between tobacco smoke and wood and charcoal smoke exposures were both tested for using stratified analysis and the logistic model. The consistency of any finding was investigated by analyses for dose-response pattern where appropriate (i.e. length and intensity of wood and charcoal smoke exposure).

\section{RESULTS}

\section{General characteristics}

A total of 60 cases and 68 controls were identified. Eight controls $(12 \%)$ were not included in the study because of logistical problems (lack of telephone, changes in home address), but they did not differ in pulmonary function variables or in demographic characteristics from the remaining controls. Overall, 60 patient cases and 60 control subjects were enrolled in the study. The distribution by case and control subject status for general and pulmonary function test variables is shown in table 1 . The mean age of the overall group was $71 \pm 9 \mathrm{yrs}$ and $14 \%$ had less than secondary education. Of the study population, $22 \%$ were current or former smokers. The mean age of smoking onset was $21 \mathrm{yrs}$.

\section{Wood smoke exposure}

Exposure to wood and charcoal smoke was frequent in both cases and controls (82\%). Mean exposure time was 16 yrs. Wood and charcoal smoke exposure was stopped at around 18 yrs of age in most of the study population. Only $20 \%$ of the subjects were a direct user of the kitchen as a cook. Table 2 shows that wood and charcoal smoke exposure were strongly associated with COPD. The association between length of the exposure (both as a continuous or categorical variable) and COPD suggested a dose-response pattern. In addition, intensity of exposure both in summer and winter was also related to COPD. Past or more recent exposure did not differ as risk factors for COPD. While working as a cook was not related to COPD, those having an indoor kitchen showed an increased risk. Regarding the type of biomass fuel, either wood or charcoal alone increased the risk of COPD, but only the combination of both was statistically significant. The association between exposure, duration of exposure and type of biomass fuel remained statistically significant after adjustment for age and smoking. Significant interactions between tobacco 


\begin{tabular}{|c|c|c|c|c|}
\hline \multirow[t]{2}{*}{ TABLE 1} & \multicolumn{4}{|c|}{$\begin{array}{l}\text { Sociodemographic, clinical and tobacco- } \\
\text { exposure characteristics }\end{array}$} \\
\hline & & Controls & $\begin{array}{c}\text { COPD } \\
\text { patients }\end{array}$ & p-value \\
\hline \multicolumn{2}{|l|}{ Subjects $n$} & 60 & 60 & \\
\hline \multicolumn{2}{|l|}{ Age yrs } & $69 \pm 9$ & $73 \pm 8$ & 0.03 \\
\hline \multicolumn{5}{|c|}{ Region of birth } \\
\hline \multicolumn{2}{|c|}{ East (Catalan areas) } & $33(59)$ & $32(60)$ & 0.94 \\
\hline \multicolumn{2}{|l|}{ South } & $17(30)$ & $15(28)$ & \\
\hline \multicolumn{2}{|c|}{ Centre (interior) } & $2(4)$ & $3(6)$ & \\
\hline \multicolumn{2}{|l|}{ North } & $4(7)$ & $3(6)$ & \\
\hline \multicolumn{2}{|c|}{ Less than secondary education } & $49(82)$ & $54(90)$ & 0.15 \\
\hline \multicolumn{2}{|l|}{ FEV 1 L } & $1.7(1.5-2.0)$ & $0.9(0.7-1.2)$ & $<0.001$ \\
\hline \multicolumn{2}{|l|}{ FEV $_{1} \%$} & $88(83-100)$ & $51(33-75)$ & $<0.001$ \\
\hline \multicolumn{2}{|l|}{ FEV $_{1 / \text { FVC } \%}$} & $76(71-80)$ & $58(45-73)$ & $<0.001$ \\
\hline \multicolumn{5}{|l|}{ Smoking } \\
\hline \multicolumn{2}{|l|}{ Never } & $52(87)$ & $42(70)$ & 0.08 \\
\hline \multicolumn{2}{|l|}{ Ex-smoker } & $4(7)$ & $8(13)$ & \\
\hline \multicolumn{2}{|l|}{ Current } & $4(7)$ & $10(17)$ & \\
\hline \multicolumn{2}{|c|}{ Ever-smoking } & $8(14)$ & $18(30)$ & 0.03 \\
\hline \multicolumn{2}{|c|}{ Smoking duration yrs } & $30(19)$ & $45(4)$ & 0.15 \\
\hline \multicolumn{2}{|c|}{ Smoking intensity cigarettes } & $20(10-20)$ & $40(30-40)$ & 0.16 \\
\hline \multicolumn{2}{|c|}{$\begin{array}{l}\text { Passive smoking in ever- and } \\
\text { never-smokers }\end{array}$} & $30(50)$ & $25(42)$ & 0.36 \\
\hline \multicolumn{2}{|c|}{ Passive smoking in never-smokers } & $29(56)$ & $23(55)$ & 0.92 \\
\hline
\end{tabular}

Data are presented as mean $\pm \mathrm{SD}, \mathrm{n}(\%)$ or median (25\% percentile- $75 \%$ percentile, unless otherwise stated). COPD: chronic obstructive pulmonary disease; FEV1: forced expiratory volume in one second; FVC: forced vital capacity.

smoking and wood or charcoal smoke exposure were not found for COPD.

\section{DISCUSSION}

The present study demonstrates a strong statistically significant association between wood and charcoal smoke exposure and COPD in Spanish females. This finding is consistent with the available literature on indoor air pollution and human health effects. The present authors believe that these findings may set the basis for epidemiological and interventional studies in other European countries.

As far as the authors are aware, this is the first study showing that domiciliary exposure to wood and charcoal smoke can be a risk factor for COPD in Europe. However, the association between indoor air pollutants resulting from wood household fuel and respiratory health has already been established in other settings. SMITH et al. [10] were the first to suggest that exposure to wood smoke could equal up to 20 pack-yrs of active exposure to cigarette smoke. Moreover, DENNIS et al. [9] showed that wood smoke exposure is associated with the development of COPD among females of low socio-economic status in Bogota (Colombia). In this study, wood smoke exposure explained around $50 \%$ of all COPD cases. Similarly, in Mexico, COPD related to wood smoke exposure has been found to affect mostly females living in the countryside in their 60s, with severe dyspnoea and cough as the outstanding complaints [13]. Pathological evidence of chronic bronchitis, and parenchymal and interstitial fibrosis with prominent anthracotic deposits was described by RESTREPO et al. [14] in male and female patients exposed to indoor wood smoke for $>10$ yrs. Fibrous and inflammatory focal thickening of the alveolar septa, as well as diffuse parenchymal anthracotic deposits, were the most prominent pathological findings (although inflammatory changes of the bronchial epithelium were also present) in lung biopsies from patients with chronic wood smoke exposure in Mexico [13]. Long-term exposure to indoor wood combustion has also been associated with squamous and small cell lung carcinomas (OR 3.1; 95\% confidence interval (CI) 0.9-9.9), as was shown by MALATS et al. [15] in a case-control study among patients with cancer from eight countries. In addition, studies assessing the effects of long-term exposure to other inhaled particulate matter have demonstrated an association with respiratory symptoms and lung function parameters [16]. Overall, the results of the present study seem consistent with a harmful chronic respiratory effect of wood and charcoal smoke exposure.

Experimental studies support the hypothesis that the high content of volatile elements during wood combustion $(80 \%)$ may account for the increased risk of pulmonary diseases. LIN et al. [17] reported that wood smoke inhalation initially (within $5 \mathrm{~min}$ ) causes airway injury, and subsequently (within $2 \mathrm{~h}$ ) produces both airway and parenchymal injury. A similar model has been investigated by JENG et al. [18], who studied the effects of exogenous surfactant supplementation and partial liquid ventilation in treating acute lung injury. Furthermore, MONTANO et al. [19] analysed the effects of wood smoke exposure on matrix metalloproteinase (MMP) activity and expression in macrophages and bronchoalveolar lavage fluid obtained from patients exposed to wood or tobacco smoke, and from control subjects. These authors demonstrated that macrophage elastolytic activity was increased in association with wood smoke exposure, with no differences between wood and tobacco smoke samples. It was concluded that chronic exposure to wood smoke increases MMP activity and expression, which might produce lung damage similarly to that observed in COPD associated with tobacco smoke.

From a public health point of view, the present study provides several relevant findings. First, a major proportion $(82 \%)$ of the present study's population was exposed to wood and charcoal smoke during a long period of their life. Since all the study sample was born in Spain, the findings of this study broke the preconception that household wood and charcoal smoke exposure is reduced in European countries compared with developing countries. Secondly, most of the present study's population referred to being exposed to wood and charcoal smoke during their childhood and youth, and most of them had been free of exposure for $\geqslant 25$ yrs prior to presenting symptoms of disease. Once more, this finding supports the hypothesis that exposure to wood and charcoal smoke in early life can be responsible for health effects in later life [20]. The present study's case-control design did not allow inference about the sequence of mechanisms (most likely to be perpetuation of inflammatory and remodelling processes in the airways) and the role of each contributing risk factors in the period between the exposure and the diagnosis of COPD. Furthermore, if long-term indoor exposure to wood smoke is a major risk factor for COPD among females in Spain, public 
TABLE 2 Crude and adjusted associations between wood and charcoal smoke exposure and chronic obstructive pulmonary disease (COPD)

\begin{tabular}{|c|c|c|c|c|c|c|}
\hline & \multirow[t]{2}{*}{ Controls } & \multirow{2}{*}{$\begin{array}{c}\text { COPD } \\
\text { patients }\end{array}$} & \multicolumn{2}{|c|}{ Univariate logistic regression } & \multicolumn{2}{|c|}{ Multivariate logistic regression ${ }^{\#}$} \\
\hline & & & OR $(95 \% \mathrm{Cl})$ & p-value & OR (95\% Cl) & p-value \\
\hline Subjects $n$ & 60 & 60 & & & & \\
\hline Wood or charcoal smoke exposure & $43(72)$ & $55(92)$ & & & & \\
\hline Exposure length yrs & $11 \pm 10$ & $21 \pm 18$ & $1.1(1.0-1.1)$ & 0.003 & $1.1(1.0-1.1)^{\bullet}$ & 0.001 \\
\hline $7-15 \mathrm{yrs}$ & $12(20)$ & $16(27)$ & $3.7(1.2-11.0)$ & 0.02 & $3.8(1.2-12.1)$ & 0.02 \\
\hline $15-20$ yrs & $15(25)$ & $16(27)$ & $2.9(1.0-8.6)$ & 0.05 & $3.7(1.2-11.5)$ & 0.02 \\
\hline$>20 \mathrm{yrs}$ & $11(18)$ & $20(33)$ & $5.0(1.0-14.9)$ & 0.004 & $6.7(2.1-21.5)$ & 0.001 \\
\hline Time from exposure yrs & $58 \pm 10$ & $52 \pm 17$ & $0.97(0.94-1.00)$ & 0.03 & $0.97(0.94-1.00)$ & 0.02 \\
\hline \multicolumn{7}{|l|}{ Time from exposure in quartiles } \\
\hline $0-49$ yrs & $11(18)$ & $17(28)$ & 1 & & & \\
\hline \multicolumn{7}{|l|}{ Exposure intensity in summer in tertiles } \\
\hline $0-6 \mathrm{~h} \cdot \mathrm{day}^{-1}$ & $33(55)$ & $9(17)$ & 1 & & $1^{\bullet}$ & \\
\hline $7-11 \mathrm{~h} \cdot \mathrm{day}^{-1}$ & $23(38)$ & $18(34)$ & $2.9(1.1-7.5)$ & 0.03 & $2.9(1.1-7.7)$ & 0.03 \\
\hline $12-24 \mathrm{~h} \cdot \mathrm{day}^{-1}$ & $4(7)$ & $26(49)$ & $23.8(6.6-86.2)$ & 0.001 & $23.3(6.3-85.7)$ & 0.00 \\
\hline Exposure intensity in winter $h \cdot$ day $^{-1}$ & $8 \pm 8$ & $15 \pm 7$ & $1.1(1.0-1.2)$ & 0.002 & & \\
\hline \multicolumn{7}{|l|}{ Exposure intensity in winter in tertiles } \\
\hline $0-6 \mathrm{~h} \cdot$ day $^{-1}$ & $29(48)$ & $9(17)$ & 1 & & $1^{\bullet}$ & \\
\hline $7-11 \mathrm{~h} \cdot \mathrm{day}^{-1}$ & $18(30)$ & $11(21)$ & $2.0(0.7-5.7)$ & 0.21 & $1.8(0.6-5.4)$ & 0.28 \\
\hline $12-24 \mathrm{~h} \cdot \mathrm{day}^{-1}$ & $13(22)$ & $33(62)$ & $8.2(3.1-21.9)$ & 0.00 & $8.1(3.0-22.3)$ & 0.00 \\
\hline Working as a cook ${ }^{+}$ & $9(15)$ & $14(25)$ & $1.9(0.7-4.8)$ & 0.18 & & \\
\hline Indoor location of kitchen ${ }^{+}$ & $44(73)$ & $49(89)$ & $3.0(1.1-8.3)$ & 0.04 & & \\
\hline
\end{tabular}

Data are presented as $\mathrm{n}(\%)$, unless otherwise indicated. OR: odds ratio; $\mathrm{Cl}$ : confidence interval. ${ }^{\#}$ : each line is a single adjusted model; ": adjusted by smoking (since age was highly correlated with yrs of exposure); + five values were missing from "working as a cook" and five from "indoor location of kitchen"; ": adjusted by age and smoking.

health implications should include measures to ameliorate the indoor levels of air pollution, for instance, by designing better ventilated dwellings, by the use of smokeless stoves, and by substituting different (smokeless) fuels. It is important to emphasise that the type of exposure caused by stoves that were previously used in Spain seems to increase the risk, which does not mean that modern stoves, quite frequently used in parts of Europe, give the same exposure and potential adverse effects. To aid diagnosis by clinical practitioners, the inclusion of a directed questionnaire regarding potential exposure to wood and charcoal smoke is advised. Some of these female patients referred to the present authors' pneumology clinic had been given a diagnosis of "persistent asthma"; in this case, information about smoke exposures would aid complementary diagnosis and treatment.

Several limitations to the present study should be considered. Since the information about exposures was obtained by interview, it is likely that cases report a higher prevalence of exposure than controls, which would somewhat bias the results of the present study. However, since there is no previous information regarding an association between wood and charcoal smoke exposure and COPD, it seems unlikely that these females reported according to such beliefs. In addition, from the current authors' point of view, it is unlikely that such a potential information bias could explain the doseresponse relationship shown between length or intensity of exposure and risk of airflow obstruction, as suggested in table 2. Another key issue in case-control designs is the selection of controls. The present authors decided to include females who consulted the pulmonary function test laboratory because of a surgical intervention (ophthalmological, traumatological or biliary surgery), under the hypothesis that none of those diseases had a relationship with either COPD or common risk factors. Therefore, the prevalence of exposure to wood and 
charcoal smoke in these females would be representative of all females living in the same geographical area. Another problem relates to small sample size. It is well known that, in the present author's area, the prevalence of COPD in females is lower than in other European countries. This is probably related to a delay in tobacco smoking habit among females, and thus it is difficult to recruit large samples of females with these diseases [21]. Even considering these weaknesses of casecontrol designs, the authors' opinion is that, in the absence of previous knowledge about this issue in the present study's setting, and given the difficulty of recruiting a large sample of females with COPD in the present study's area, a case-control design would be more efficient than another design and necessary before other designs are planned. Following these observations, the present authors would strongly suggest including information about wood and charcoal exposure in ongoing European cohorts in order to replicate the current findings.

\section{Conclusions}

The present study supports an association between wood and charcoal exposure and chronic obstructive pulmonary disease existing not only in developing countries, but also in European societies, such as Spain. Further studies assessing whether this association also exists in other European societies are warranted.

\section{ACKNOWLEDGEMENTS}

The authors gratefully acknowledge D. Maldonado (Fundación Neumológica Colombiana, Bogotá, Colombia) and J.M. Broquetas (Hospital del Mar, Barcelona, Spain) for valuable suggestions on the study.

\section{REFERENCES}

1 Boman BC, Forsberg AB, Jarvholm BG. Adverse health effects from ambient air pollution in relation to residential wood combustion in modern society. Scand J Work Environ Health 2003; 29: 251-260.

2 Garcia-Aymerich J, Barreiro E, Farrero E, et al. Patients hospitalised for chronic obstructive pulmonary disease (COPD) have a high prevalence of modifiable risk factors of exacerbation - EFRAM study. Eur Respir J 2000; 16: 1037-1042.

3 Miller A. Pulmonary function tests in clinical and occupational lung disease. New York, Grunne \& Stratton, 1986; pp. 187-194.

4 Siafakas NM, Vermeire P, Pride NB, et al. Optimal assessment and management of chronic obstructive pulmonary disease (COPD). The European Respiratory Society Task Force. Eur Respir J 1995; 8: 1398-1420.

5 Barberà JA, Peces-Barba G, Agustí AGN, et al. Clinical guidelines for the diagnosis and treatment of chronic obstructive pulmonary disease. Arch Bronconeumol 2001; 37: 297-316.

6 American Thoracic Society. Standards for the diagnosis and care of patients with chronic obstructive pulmonary disease. Am J Respir Crit Care Med 1995; 152: Suppl. 1, S77-S121.

7 Medical Research Council. Report on definition and classification of chronic bronchitis. Lancet 1965; 9: 775-779.

8 Pulmonary terms and symbols. A report of the ACCP-ATS Joint Committee. Chest 1975; 67: 583-593.

9 Dennis RJ, Maldonado D, Norman S, Baena E, Martinez G. Woodsmoke exposure and risk for obstructive airways disease among women. Chest 1996; 109: 115-119.

10 Smith KR, Aggarway AL, Dave RM. Air pollution and rural biomass fuel in developing countries: a pilot village study in India and implications for research and policy. Atmospher Environ 1983; 17: 2343-2362.

11 Kramer MS. Clinical epidemiology and biostatistics. New York, Springer-Verlag, 1988; p. 67.

12 Schelesselman J. Case-control studies: design, conduct and analysis. New York, Oxford University Press Inc., 1982.

13 Sandoval J, Salas J, Martinez-Guerra ML, et al. Pulmonary arterial hypertension and cor pulmonale associated with chronic domestic woodsmoke inhalation. Chest 1993; 103: 12-20.

14 Restrepo J, Reyes $\mathrm{P}$, de Ochoa P, et al. Neumoconiosis por inhalación de humo de leña [Pneumoconiosis due to inhalation of wood smoke]. Acta Med Colomb 1983; 8: 191-204.

15 Malats N, Camus-Radon AM, Nyberg F, et al. Lung cancer risk in nonsmokers and GSTM1 and GSTT1 genetic polymorphism. Cancer Epidemiol Biomarkers Prev 2000; 9: 827-833.

16 Brunekreef B, Holgate ST. Air pollution and health. Lancet 2002; 360: 1233-1242.

17 Lin YS, Ho CY, Tang GJ, Kou YR. Alleviation of wood smoke-induced lung injury by tachykinin receptor antagonist and hydroxyl radical scavenger in guinea pigs. Eur J Pharmacol 2001; 425: 141-148.

18 Jeng MJ, Kou YR, Sheu CC, Hwang B. Effects of exogenous surfactant supplementation and partial liquid ventilation on acute lung injury induced by wood smoke inhalation in newborn piglets. Crit Care Med 2003; 31: 1166-1174.

19 Montano M, Beccerril C, Ruiz V, Ramos C, Sansores RH, Gonzalez-Avila G. Matrix metalloproteinases activity in COPD associated with wood smoke. Chest 2004; 125: 466-472.

20 Barker DJP. Rise and fall of Western diseases. Nature 1989; 338: 371-372.

21 Pena VS, Miravitlles M, Gabriel R, et al. Geographic variations in prevalence and underdiagnosis of COPD: results of the IBERPOC multicentre epidemiological study. Chest 2000; 118: 981-989. 